\title{
Social and Economic Factors of Sports Activity in Russian Regions
}

\author{
T.V. Kramin ${ }^{1,4^{*}}$, M.R. Miftahov ${ }^{2,4}, W$. Andreff $^{3}$, and S.B. Eroshkina ${ }^{4}$ \\ *Corresponding author: kramint $@$ mail.ru. \\ ${ }^{1}$ Kazan Innovative University named after V. G. Timiryasov, Kazan, Russia, \\ ${ }^{2}$ Ministry of Sports of the Republic of Tatarstan, Kazan, Russia, \\ ${ }^{3}$ French Ministry of Sports, Paris, France \\ ${ }^{4}$ Federal Research Center of Physical Culture and Sports, Moscow, Russia
}

\begin{abstract}
In this study, the key factors of sports activity in the Russian regions were identified and substantiated. The regional panel data for the period 2007-2017 was used as data for the study. It is shown that traditional material factors are highly significant in models for assessing the level of sports activity in the Russian regions. These include, in particular, the following indicators: the one-time carrying capacity of sports facilities, the per capita expenditures for physical culture and sports development, the number of sports facilities per 100 thousand people, the number of full-time physical culture and sports personnel per capita. Consequently, forecasting based on them will give a stable and reliable result.

Along with the evidence of the significance of the material factors of sports activity, a justification of the influence of a number of intangible, institutional factors is given. Such factors include the awareness about the benefits of systematic physical education and sports, institutions of public encouragement and support for those involved in sports and physical culture, etc.
\end{abstract}

Keywords: factors of sports activity, physical activity, physical culture, sports, institutions, digital economy.

\section{Introduction}

Development of mass sport and physical culture of the population is an important component of social-economic development of any country. One of the key indicators of mass sport development is the share of population systematically engaged in physical culture and sport.

According to the data of Sport and Active Society Commission under the International Olympic Committee, in 2008 in some countries the share of people regularly engaged in physical culture and sport was $60-70 \%$. These countries include Brazil, Iceland, Columbia, Finland, France, Sweden, and Japan. In most of the economically developed countries this indicator is over $40 \%$.

In compliance with the "Strategy of physical culture and sport development in the Russian Federation up to 2020", in 2020 the share of citizens systematically engaged in physical culture and sport must be not less than $40 \%$.

In particular, a report by E.P. Kakorina [1] stated that the most disadvantageous period for sport development in the RSFSR and Russia was 1975-1995. In that period, the analyzed indicator of sport activity decreased 5 times (from $37.5 \%$ to $7.1 \%$ ). Since 1995 , the situation was gradually recovering.

In this context, it is important to note the systemic understanding of physical culture and sport development in the USSR demonstrated by foreign scholars [2], who highly evaluated the USSR public institutions in this sphere. Physical activity of the population depends on many individual material and nonmaterial factors, including gender, age, social environment, income level, educational level, etc. [3].

The main obstacles for doing physical culture and sport are the lack of spare time and motivation. According to P. Edwards and A. Tsouros, overcoming these barriers plays the key role in solving the problem of physical culture and sport activation [4]. In should be noted that most of the conclusion of foreign authors cited in the present work are confirmed by the Russian researchers (see below).

A research by A. Bauman et al. showed a lower physical activity in women compared to men, as well as heterogeneous influence of educational level [5].

The social-psychological factors of sport activity are:

1) the social-economic status of a person, which determines the degree of sport infrastructure accessibility; this is especially important for low income groups [6,7];

2) the family traditions, the social environment, support of colleagues and friends $[8,9,10]$;

3) self-confidence, ability to get pleasure and benefits from physical culture and sport [11, 12];

4) the established way of living and habits [13].

Physical activity is promoted by the development of city environment, while its influence can be both positive and negative. L. Frank et al. note that the availability of convenient walking sites with quality surface stimulates regular walks 
[14]. Researchers $[15,16]$ showed that the increase of such zones leads to the growth of physical activity. Others emphasize that physical activity decreases due to urbanization processes and broader use of automobile transportation $[17,18]$.

Notably, according to the data of All-Russia Center for Public Opinion Research, the reasons impeding engagement on sport in Russia in 2008 were: "lack of spare time" (39\%), "lack of desire" (41\%), "state of health (20\%) [1].

It should be noted that these data are close to the results of a more recent poll [19]. The above data allow defining the main directions of researching the factors of sport activity of the Russian population.

The physical activity of the population is one of the most important components of the social life of any country. Development of mass sport and physical culture of the population is an important component of social-economic development of any country. One of the key indicators of mass sport development is the share of population systematically engaged in physical culture and sport. According to the data of Sport and Active Society Commission under the International Olympic Committee, in 2008 in some countries the share of people regularly engaged in physical culture and sport was 60-70\%. Presently this indicator in Russia does not reach 40\%.

In Russia, a lot is being done to increase the sports activity of the population - new sports facilities are being built and existing one are reconstructed, national and regional sports events are being held with the assistance of regional and federal authorities. To increase the effectiveness of this work, it is necessary to identify the most important factors of the sports activity of the population. Their identification and justification will allow for the implementation of a more balanced and productive regional policy in the field of physical education and mass sport.

The objective of this research is to reveal and quantitatively estimate the influence of the main factors of sport activity in order to develop efficient regional policy in the sphere of physical culture and mass sport. In particular, it is essential to reveal the main barriers and limitations, as well as the underused reserves and potentials of increasing sport activity. The regional agenda will help to reveal the best practices in managing the system of physical culture and mass sport in the Russian regions and spread them in other subjects of the Russian Federation.

\section{Methods}

The main tool of this research is econometric modeling. We formulate and test a number of hypotheses to identify factors of sports activity of the population in the Russian regions based on a literature review based on the official regional statistics of Russia.

The research data are regional panel data for Russia in the period 2007-2017 [20]:

1. The share of population systematically engaged in physical culture and sport in the total number of the population (per cent). In the constructed models, this indicator is denoted N1 with the two last digits of a calendar year. For example, N115 stands for the indicator for the year 2015;

2. The share of students systematically engaged in physical culture and sport in the total number of student (standed for N2).

Taking into account the above said, the indicators of potentially significant factors of sport activity (the explanatory variables) are: the number of sport facilities (stadiums, swimming pools, other constructions) per 100 thousand of population (units, standed for FPC); one-time capacity of sport facilities (\%, standed for EP); expenditures for the development of physical culture and sport per capita (a year, thousand rubles, standed for ZP); the number of permanent staff members in physical culture and sport per capita by the subjects of the Russian Federation (standed for WPC).

The overall objective of the modeling is to reveal and substantiated the factors (and respective indicators) facilitating the growth of sport activity in the Russian regions and municipalities and the degree of their impact.

\section{Results}

Analysis of data was carried out on the basis of formulating and checking the following hypotheses:

1. The level and dynamic of sport activity of the population in the Russian regions (indicator N1 in the models) depends on the level and dynamic of one or several explanatory variables, listed above.

2. The level and dynamic of sport activity of the students in the Russian regions (indicator N2 in the models) depends on the level and dynamic of one or several explanatory variables, listed above.

The results of testing the hypotheses are shown in Table 1. It presents the models of estimating the factors of sport activity of the population in the Russian regions. The dependent variables are N1 and N2; modeling was carried out with panel data; fixed spacing effects based on Hausman test results were applied. The models are well specified: the coefficients at all explanatory variables are highly significant. The models possess good explanatory power: values of $\mathrm{R}^{2}$ show that the models explain over $90 \%$ of differences in the values of dependent variable in the Russian regions. Adding the lag variables allowed overcoming serial autocorrelation, which is explicitly reflected in the values of Durbin-Watson statistics. 
Table 1. Models for estimating the factors of sport activity in the Russian regions Dependent variables: N1, N2. Fixed effects, period 2011-2016. Regions included: 82 Panel least-squares method, total number of panel observations: 492

\begin{tabular}{|c|c|c|}
\hline Dependent variable & N1 & N2 \\
\hline Variable $\backslash$ Model number & 1 & 2 \\
\hline C & $-0.096899(0.0000)$ & $-0.064320(0.0544)$ \\
\hline EP & $0.024714(0.0008)$ & $0.071416(0.0001)$ \\
\hline ZP & $0.001529(0.0000)$ & $0.002149(0.0023)$ \\
\hline ZP(-1) & $0.001206(0.0000)$ & \\
\hline FPC & $0.069401(0.0000)$ & $0.071016(0.0003)$ \\
\hline WPC & $14.61097(0.0028)$ & \\
\hline WPC(-1) & & $29.83800(0.0076)$ \\
\hline N1(-1) & $0.690421(0.0000)$ & \\
\hline N2(-1) & & $0.750549(0.0000)$ \\
\hline $\mathrm{R}^{2}$ & 0.947856 & 0.919645 \\
\hline F-statistics & 84.41084 & 53.89678 \\
\hline Probability by F-statistics & 0.000000 & 0.000000 \\
\hline Durbin-Watson statistics & 1.923263 & 2.331804 \\
\hline
\end{tabular}

Source: Authors.

Note: specification of (-1) in denotations of variables shows a time lag of one period (a year). Figures in brackets are null-hypothesis probabilities by t-statistics for coefficients of independent variables.

Table 1 shows that many hypotheses of groups 1 and 2, described above, were conformed. Comparing models 1 and 2 in Table 1, it should be noted that in general the impact of the analyzed factors on the indicators of sport activity N1 and N2 are similar. One should note the high dependence of the current values of dependent variables on their previous year values. Thus, in the studied period, stable trajectories of sport activity development are formed in the Russian regions. The indicators "One-time capacity of sport facilities" (EP), expenditures for the development of physical culture and sport per capita (ZP), the number of sport facilities per 100 thousand of population (FPC), and the number of permanent staff members in physical culture and sport per capita by the subjects of the Russian Federation (WPC) are significant in the models explaining the differences in the Russian regions by the level of their sport activity.

Thus, the material factors, such as availability of sport facilities, the level of per capita expenditures for the development of physical culture and sport in the Russian regions, and others, significantly influence the sport activity of their population. The model specification proves the necessity to include lag explanatory variables into them, which demonstrates their so called delayed (in time) effect on the explained variable.

Despite the high quality of the built models, judging by the $\mathrm{R}^{2}$ value, there are also factors of sport activity not taken into account in these models. Besides, the dynamics of sport activity in the Russian regions takes place along distinctly trackable trajectories, which is displayed, in particular, by autocorrelation of time series of the relevant variables. There are also various trajectories of sport activity indicators in different Russian regions. These facts testify to the necessity of taking into account the non-material, institutional factors of sport activity, as well as of revealing and registering the best practices in the Russian regions.

\section{Conclusion}

The present research identifies and substantiates the key factors of sport activity in the Russian regions. It should be noted that the presented models of estimating the factors of sport activity are well specified: the coefficients at all explanatory variables, included in them, are highly significant; the use of lag variables enabled to actually exclude autocorrelation of the model errors, which shown by the values of Durbin-Watson statistics. The models possess good explanatory power $\left(\mathrm{R}^{2}\right.$ of the models exceeds $\left.90 \%\right)$. Consequently, forecasting based on them will yield a reliable result.

In future research, we plan to continue the study of the above issues, in particular, in the sphere of identifying the new institutional factors of sport activity, and to formulate new proposals for taking these factors into account when forming the regional policy in the field of physical culture and sports and developing new institutions. 


\section{References}

1. E.P. Kakorina, Attitude of the population to engagement in physical culture and sport. Healthcare in Russia, 11, 137-140 (2011). [in Rus.].

2. O’Mahony, Sport in the USSR: Physical culture - Visual culture (University of Chicago Press, Chicago, 2006).

3. T.S. Solov'eva, The level of physical activity and motivation of urban population for physical exercises and sports. Issues of Territorial Development, 3(83), 119-136 (2016). [in Rus.].

4. P. Edwards, A. Tsouros, Promoting physical activity and active living in urban environments. The role of local governments. The solid facts (World Health Organization, Geneva, 2006).

5. A.E. Bauman, R.S. Reis, J.F. Sallis, J.C. Wells, R.J. Loos, B.W. Martin, Correlates of physical activity: Why are some people physically active and others not? Lancet, 380 (9838), 258-271 (2012). DOI: 10.1016/S01406736(12)60735-1.

6. L.H. McNeill, M.W. Kreuter, S.V. Subramanian, Social environment and physical activity: A review of concepts and evidence. Social Science and Medicine, 63(4), 1011-1022. (2006).

7. M. Braubach, M.E. Héroux, N. Korol, E. Paunovic, I.A. Zastenskaya, The value of housing conditions and urban environment for the health. Hygiene and Sanitary, 1, 9-15 (2014). [in Rus.].

8. K. Young, M. Atkinson (Eds.), Qualitative research on sport and physical culture. Research in the Sociology of Sport, 6 (Emerald Group Publishing Limited, Bingley, 2012). DOI: 10.1108/S1476-2854(2012)0000006015.

9. S.L. Gustafson, R.E. Rhodes, Parental correlates of physical activity in children and early adolescents. Sports Medicine, 36(1), 79-97 (2006).

10. C.A. Yao, R.E. Rhodes, Parental correlates in child and adolescent physical activity: A meta-analysis. International Journal of Behavioral Nutrition and Physical Activity, 12(10) (2015). DOI: 10.1186/s12966-015-0163-y.

11. C. Currie, Ch. Roberts, A. Morgan, R. Smith, W. Settertobulte, O. Samdal, V. Barnekow Rasmussen (Eds.), Young people's health in context. Health Behaviour in School-aged Children (HBSC) study: International report from the 2001/2002 survey (World Health Organization, Copenhagen, 2004).

12. F.J. Van Lenthe, J. Brug, J.P. Mackenbach, Neighbourhood inequalities in physical inactivity: The role of neighbourhood attractiveness, proximity to local facilities and safety in the Netherlands. Social Science and Medicine, 60(4), 763-775 (2005).

13. D.A. Kurakov, N.L. Maltseva, Physical inactivity is a result of urbanization or laziness? (Materials of medicosociological study). Sociology of a City, 3, 74-81 (2014). [in Rus.].

14. L.D. Frank, J.F. Sallis, T.L. Conway, J.E. Chapman, B.E. Saelens, W. Bachman, Many paths from land use to health: Associations between neighborhood walkability and active transportation, body mass index, and air quality. Journal of the American Planning Association, 72(1), 75-87 (2006).

15. L. Frank, S. Kavage, T. Litman, Promoting public health through Smart Growth: Building healthier communities through transportation and land use policies and practices (2006). URL: https://www.vtpi.org/sgbc health.pdf. Accessed: 17.09.2019.

16. A.T. Kaczynski, K.A. Henderson, Parks and recreation settings and active living: A review of associations with physical activity function and intensity. Journal of Physical Activity and Health, 5(4), 619-632 (2008).

17. B.E. Saelens, J.F. Sallis, J.B. Black, D. Chen, Neighbourhood-based differences in physical activity: An environment scale evaluation. American Journal of Public Health, 93, 1552-1558 (2003). DOI: 10.2105/AJPH.93.9.1552.

18. R.L. Mackett, B. Brown, Transport, physical activity and health: Present knowledge and the way ahead (Centre for Transport Studies University College London, London, UK, 2011).

19. N.V. Zybunovskaya, A.N. Pokida, Spare time and leisure as conditions for forming healthy lifestyle of the Russian population. Izvestiya of Saratov University. Series: Sociology. Politology, 11(2), 37-41 (2011).

20. Federal Agency of State Statistics, Annual report "Regions of Russia. Social-economic indicators" (2018). URL: https://www.gks.ru/free_doc/doc_2018/region/reg-pok18.pdf. Accessed: 17.09.2019. [in Rus.]. 